\title{
THE RAVEN E O SEU VOO PARA A LÍNGUA BRASILEIRA DE SINAIS
}

\author{
Emerson Cristian Pereira dos Santos* \\ Universidade Federal do Ceará/Instituto Federal do Ceará
}

\begin{abstract}
Resumo: The raven já recebeu diversas traduções desde que foi publicado em 1845, e vários tradutores já se aventuraram a compreender e transferir para outras culturas toda a trama envolvida com o corvo e sua resposta simples, mas ao mesmo tempo fria e angustiante. Agora, esse enigmático corvo pousou na cultura surda brasileira, e este artigo foi elaborado para comentar algumas estratégias tradutórias realizadas para a LIBRAS.

Palavras-chaves: The raven. LiBRAS. Tradução intercultural. Tradução literária
\end{abstract}

\section{THE RAVEN AND ITS FLIGHT TO THE BRAZILIAN SIGN LANGUAGE}

\begin{abstract}
Poe's The raven has received several translations since it was first published in 1845, with many translators having already ventured into trying to understand its plot, which centers around a raven and its simple, albeit cold and terrifying, reply to a lonely bereaved lover, in an effort to transpose it into other languages and cultures. Now this enigmatic bird has come to visit the Brazilian deaf culture. This article discusses some strategies used in my translation of the poem into LIBRAS (Brazilian Sign Language)

Key-words: The raven. LSB. Intercultural translation. Literary translation.
\end{abstract}

\footnotetext{
* Emerson Cristian Pereira dos Santos: Mestre pelo Programa de Pós-Graduação em Estudos da Tradução (POET) da Universidade Federal do Ceará (2016). Professor de Literatura do Instituto Federal do Ceará. Pesquisador do Grupo de Pesquisa e Estudo em Educação, Linguística e Letras (GPEL), também do Instituto Federal do Ceará. Iguatu, Ceará, Brasil. E-mail: em.cristian@gmail.com
} 


\section{Introdução}

Um jovem em luto esforça-se para continuar sua leitura, enquanto o vento empurra contra a janela os galhos de uma árvore; os ponteiros do relógio marcam meia-noite; a atmosfera parece sombria e, em cima da porta da sala, um busto de Pallas Atena, deusa grega da sabedoria, agora serve de poleiro para um pássaro agourento mais assemelhado a um criado mortuário do que a um corvo. Da boca do jovem, várias perguntas, e do bico da ave uma única resposta a todos os questionamentos: nevermore ${ }^{1}$. Isso é apenas parte do cenário sinistro elaborado por Poe em The raven. Mesmo que, como leitores, empenhemos esforços para fugir desse ambiente sombrio, nossas tentativas serão em vão, porque a linguagem perturbadora leva-nos a um espaço desolador desde o primeiro verso da primeira estrofe: Once upon a midnight dreary, while I pondered weak and weary ${ }^{2}$. Neste, a expressão midnight dreary ${ }^{3}$ faz-nos refletir sobre o fim e o início de algo, mais precisamente o fim da vida e o início da morte. Essa compreensão de encerramento da existência e começo da ausência também está no início da segunda estrofe, onde temos a mesma sensação, quando dezembro é usado tanto como apontamento do fim como perspectiva do começo de um novo ano, na mesma medida em que a meia-noite é de um dia. Mas apesar dessas associações/metáforas poéticas, são a ave e sua palavra as responsáveis por ampliar uma atmosfera lúgubre e infeliz, repleta de referências a um profundo estado de tristeza, de melancolia, provocado pela perda precoce de Lenore, a amada daquele jovem.

The raven já desafiou muitos tradutores de línguas oral-auditivas (Machado de Assis, Fernando Pessoa, Charles Baudelaire, Stephane Mallarmé, Enrique González Martínez) que se valeram da escrita e das propriedades fonéticas para oferecer aos leitores da

\footnotetext{
${ }^{1}$ Nunca mais.

${ }^{2}$ Numa meia-noite triste, enquanto eu refletia fraco e cansado.

${ }^{3}$ Meia-noite triste.
} 
língua de chegada uma linguagem angustiante parecida com aquela contida no original. Agora, não são as palavras as desafiadas, nem a escrita, mas, em seu lugar, os sinais e o próprio corpo do tradutor que recebem a incumbência de transportar a estrutura intricada do poema para uma língua visual. Como esses aspectos poderiam ser representados através das mãos, dos movimentos corporais e das expressões faciais? Quais estratégias o corpo poderia utilizar para aproximar-se das características do texto original, a ponto de promover no espectador da cultura de chegada uma sensação aproximada à do leitor da cultura de partida? Seria possível manter, na tradução em língua de sinais, uma estrutura poética parecida com a do original? Essas perguntas foram apenas algumas que antecederam o pouso do corvo de Poe na cultura surda brasileira, por meio da tradução ${ }^{4}$ originada nas reflexões teóricas oriundas das atividades e seminários desenvolvidos no âmbito do Programa de Pós-Graduação em Estudos da Tradução (POET) da Universidade Federal do Ceará (UFC). Este artigo ${ }^{5}$ surge para comentar apenas parte do trabalho, uma vez que, obviamente, não haveria espaço para detalhar todo o processo de construção de uma tradução tão rica e desafiadora como esta, que se iniciou em meados de 2015 e foi concluída em 2016.

Após uma breve reflexão sobre a importância de se buscar uma tradução intercultural, e de se analisar alguns aspectos estruturais e poéticos do texto-fonte, este trabalho descreve parte das estratégias utilizadas na tradução de The raven para a Libras. Somente alguns pontos considerados mais relevantes foram destacados, tais como os pressupostos funcionalistas de Has J. Vermeer (1989b) e de Christiane Nord (1991), a importância de se criar um ambiente funcionalmente representativo para a cultura de chegada e a (des) construção dos aspectos estruturais (estrofes, versos, rimas) durante a tradução.

\footnotetext{
${ }^{4}$ A tradução pode ser acessada em: https://youtu.be/kQ8GjgrVIDc.

${ }^{5}$ Sou muito grato ao meu orientador no mestrado, professor Dr. Robert de Brose, que, no pouco tempo que ele dispunha, comentou este trabalho e sugeriu importantes considerações.
} 


\section{A tradução como artefato cultural}

Muitas vezes, parece não haver uma conexão consciente por parte do tradutor de que suas atividades conectam linguagem, cognição e cultura, e não é preciso muito esforço para percebermos a existência dessa forte relação nas traduções. Evidentemente, não são essas as únicas facetas a se pensar ou explorar em um trabalho tradutório, muito menos é imperioso que elas constem em todas as análises, mas algumas há que, inevitavelmente, exigem reflexões sobre essa ação conjunta, ou, ao menos, sobre uma delas, pois priorizar apenas uma na análise não significa negar o vínculo. Este artigo, por exemplo, explora a atividade tradutória a partir do ponto de vista intercultural, refletindo sobre a linguagem e estrutura poéticas e, ao mesmo tempo, sobre a possibilidade de oferecer um texto final funcionalmente representativo para cultura de chegada. Certamente, seria igualmente importante investigar os processos cognitivos envolvidos, ou verificar como a cultura-alvo recepciona as metáforas conceituais, ou, ainda, examinar como a linguagem reflete a cultura de chegada em comparação com a cultura de partida. Para este trabalho, no entanto, em virtude do caminho percorrido pela tradução e pelos limites impostos a este artigo, torna-se capital examinar como a tradução explorou alguns recursos poéticos na tentativa de transformá-la em um artefato da cultura surda brasileira, através da elaboração de estratégias que priorizaram o aspecto visual, sem deixar de lado alguns aspectos formais do poema original.

Um ponto inicial adequado seria, portanto, explicitar o referencial teórico a partir do qual o conceito de "cultura", como adotado e entendido por este trabalho, é entendido e fundamentado. A esse respeito, um viés importante é aquele fornecido pela visão das ciências sociais, principalmente da antropologia, que agrega pontos de vista respeitáveis não apenas de antropólogos mas também de linguistas, sociolinguistas e linguistas cognitivos como Hudson (1996), D’Andrade (1995), Shore (1996), Strauss e Quinn (1997), Kövecses (2005, 2010) e Lyons (2013) que, basicamente, definem cultura como um conjunto de conhecimentos adquiridos socialmente e compartilhados por um 
grupo de pessoas de uma determinada comunidade. A essa definição, poderíamos acrescentar o ponto de vista de Witherspoon (1977, p. 03), ao conceituar cultura como "[...] a symbolic code through which messages are transmitted and interpreted. But, more than a code, culture is a set of conceptions of and orientations to the world, embodied in symbols and symbolic forms".

Como todo código simbólico transmite mensagens, então há algo nas culturas a ser interpretado. Para qualquer interpretação que tente corromper o código, deveremos ter reações de seus membros que podem ser as mais extremas possíveis. Uma maneira de perceber isso seria olhar para culturas diferentes da nossa, a fim de tentar verificar os limites impostos pelos códigos, muitas vezes interpretados não através da mensagem contida neles, mas por meio de uma outra que lhes é estranha e não lhes pertence. Por exemplo, para uma cultura enraizada na audição, o implante coclear afigura-se como uma solução para os surdos, já que os absorveria no pano de fundo de sua própria cultura; para os surdos, contudo, a solução é a permanência e a difusão de sua cultura através da salientação, ou até mesmo do contraste com a cultura auditiva dominante, não sua extinção. Dessa forma percebemos como cada grupo impõe limites instituídos socialmente.

Por meio dessa perspectiva, é possível constatar que os surdos também possuem sua cultura, sem deixar de ter os traços culturais majoritários de seu país, porque, por um lado, estão em contato constante com os ouvintes e, por outro, compartilham com seus pares um conjunto muito singular de entendimentos: dominam o Português como língua estrangeira, mas possuem a sua própria; estudam em escolas de ouvintes, mas gostariam de desfrutar de um espaço educacional bilíngue; aprendem a literatura ouvinte, ainda que adaptada ${ }^{7}$ para lhes fazer sentido, porque nada os fascina mais

\footnotetext{
${ }^{6}$ [...] um código simbólico pelo qual várias mensagens são transmitidas e interpretadas. Mais do que um código, a cultura é um conjunto de concepções e de orientações para o mundo, repleto de símbolos e formas simbólicas.

${ }^{7}$ Comumente, a literatura ouvinte recebe adaptações quando traduzida para a LIBRAS. Exemplos disso são os clássicos "O patinho feio", "Chapeuzinho vermelho" e "Cinderela",
} 
do que uma literatura visual produzida por mãos, expressões faciais e corporais que lhes parecem naturais, onde as aliterações e assonâncias cedem espaço para morfismos e combinações paramétricas tão bem elaboradas, que se até mesmo um ouvinte fluente em LIBRAS não estiver suficientemente imerso na cultura surda, ficará totalmente à margem do entendimento; além do mais, ao longo do tempo, eles preservaram e garantiram seus contos, poemas e prosas em línguas de sinais. Enfim, exercem sua alteridade sem desprezar a do outro. Em outras palavras, e adaptando o que Kövecses (2010, p. 740) tem a dizer sobre cultura, da mesma forma, os surdos também "[...] identify objects and events in similar ways, they find or do not find behavior appropriate in certain situations, they create objects, texts, and discourses that other members of the group find meaningful, and so forth" ${ }^{8}$.

Inegavelmente, a língua de sinais desempenha um papel muito importante na comunidade surda. Na verdade, ela é o seu artefato cultural mais significativo. No entanto, aplicando as contribuições da Linguística Cognitiva (veja Lakoff e Johnson (2003, 1999) e Kövecses (2005)), meu entendimento aponta para o corpo do sujeito e suas experiências corpóreo-culturais como sendo dois dos principais motivadores para o surgimento da cultura surda e da língua de sinais. Como nossas experiências corporais possuem uma função fundamental em nossas conceitualizações, se pensarmos na configuração de nossos corpos e, consequentemente, na relação deles com as coisas do mundo, perceberemos seu engajamento em moldar boa parte de nosso sistema conceitual, também estruturado em virtude de nossas experiências culturais. Por exemplo, nossos corpos são projetados para perceber somente a luz visível, ondas captadas pelos olhos, mas caso pudéssemos acessar, em nosso dia a dia, todo o espectro eletromagnético, então nosso sistema concei-

que são recontados em LIBRAS como "O patinho surdo", "Chapeuzinho vermelho surda" e "Cinderela surda".

${ }^{8}$ [...] identificam objetos e eventos de forma equivalente, encontram, ou não, um comportamento apropriado em certas situações, criam objetos, textos e discursos nos quais outros membros do grupo encontram significado, e assim por diante.

Cad. Trad., Florianópolis, v. 37, $\mathrm{n}^{0}$ 2, p. 132-158, mai-ago 2017 
tual seria ampliado e estabeleceríamos mais relações entre o mundo e nossa forma de conceituá-lo. A cultura na qual estamos inseridos também possui um papel essencial em nossas conceitualizações. Em sua pesquisa, Santos (2016) demonstrou que a metáfora conceitual, por exemplo, surge e varia também em virtude de fatores não linguísticos diversos, entre eles estão as experiências culturais e as ideologias, demonstrando que é por meio da cultura que nos comportamos aproximadamente da mesma maneira que nossos pares culturais, sem ultrapassar os limites impostos pelo código.

Quando pensamos na interferência do corpo em nossa cognição, notaremos que toda uma cultura surda só surgiu quando aqueles que possuíam uma experiência sensorial distinta da dos demais começaram a descobrir-se, a agrupar-se e a perceberem a necessidade de se comunicar por meio de seus corpos. E foi a surdez, essa particularidade corporal, uma das principais responsáveis por moldar parte do sistema conceitual e fazer com que o surdo identificasse, experienciasse e explorasse o mundo através de sua ferramenta simbólica mais importante: a língua de sinais. Mesmo assim, na literatura, em virtude da perspectiva ouvintista, "surdez" parece ser a vilã, marca de patologia, de deficiência, ou mesmo, atenuando um pouco, de limitação auditiva, e exige muita coragem de um autor ou pesquisador para utilizar tal palavra em seu trabalho e não ser rechaçado ou autuado como antagonista. Aqui, ela não está relacionada com nenhum desses conceitos, mas com o fato de ser uma experiência corporal que proporcionou o surgimento de várias línguas de sinais e culturas surdas espalhadas pelo mundo. Por isso a surdez não pode ser vista, de forma alguma, como falha. Ela é uma característica do corpo que foi capaz de fazer o que a audição não faria: proporcionar o surgimento de culturas surdas. Portanto, o corpo incitou e a língua de sinais prosseguiu com o trabalho em originar uma teia de significâncias tecida, entendida e compartilhada por seus membros.

Quando levamos esses entendimentos para o campo da tradução, perceberemos a responsabilidade do tradutor de tornar o produto final em mais um artefato do código simbólico. Dependendo das 
características do texto, formular uma tradução por meio de um processo culturalmente funcional é crucial, pois o profissional não está diante apenas de sistemas linguísticos diferentes. À frente dele estão compartilhamentos culturais e ideologias distintos. Perspectivas como essas são importantes porque ultrapassam o ponto de vista estritamente vinculado aos sistemas linguísticos, e conduzem o tradutor a um terreno extralinguístico e intercultural. A questão, portanto, ganha um novo cenário, bastante discutido e planificado por pesquisadores e estudiosos como Hans J. Vermeer, Katharina Reiß e Christiane Nord. Estes enxergam a tradução pelo enfoque intercultural, e estabeleceram importantes proposições embasadas nesse entendimento. Uma delas pode ser encontrada em uma das afirmativas mais conhecidas de Vermeer (1989b), em sua Teoria do Escopo, elencada por Nord (1997, p. 29): "translate/interpret/speak/write in a way that enables your text/translation to function in the situation in which it is used and with the people who want to use it and precisely in the way they want it to function ${ }^{9 "}$. Essa ideia reforça a visão de cultura como um conjunto simbólico específico e próprio de um povo.

Tal percepção funcional leva-nos à reflexão de que nem tudo explícito no texto-alvo pode ser objeto de tradução, nem tudo que é objeto de tradução pode estar contido explicitamente no texto-alvo, porque há uma grande diversidade de nuanças simbólicas ultrapassando os textos, embora haja limites, nuanças que só podem ser encontradas nesse conjunto de interesses culturais. Essa extrapolação textual é descoberta quando o olhar volta-se para fatores extratextuais, tão bem apontados por Nord (1991), tais como emissor, intenção do emissor, receptor, meio pelo qual o texto é conduzido, lugar, tempo, propósito (motivo) e função textual. Obviamente, a lógica de uma tradução intercultural não está em priorizar esses fatores em detrimento dos intratextuais - tema, conteúdo, pressuposições, estruturação, elementos supra-segmentais e efeitos do texto - mas estabelecer uma relação entre ambos.

${ }_{9}$ Traduzir/interpretar/falar/escrever de uma forma que permita que o seu texto/tradução funcione na situação em que ele é usado e com as pessoas que querem usá-lo e, precisamente, na forma como essas pessoas desejam que funcione.

Cad. Trad., Florianópolis, v. 37, no 2, p. 132-158, mai-ago 2017 


\section{Interpretando e traduzindo: promovendo um ambiente funcionalmente representativo na tradução}

Em The raven, não se pode negar que vários problemas tradutórios se revelam quando são analisados previamente os aspectos linguísticos e culturais do texto de partida, a começar pela própria ave ${ }^{10}$ que não pertence à fauna brasileira, e pode dificultar uma recepção pela cultura de chegada, mesmo parcialmente. No entanto, os julgamentos a respeito do corvo, e que acabaram firmando-se no Brasil, chegam principalmente de textos, seriados e filmes norte-americanos, e revelam alguns entendimentos simbólicos da cultura de partida relacionados a esse pássaro, tais como solidão, morte, agouro e azar, além de muitas vezes ele estar associado a um emissário do "além". Fantasia ou não, no poema, o corvo tem a incumbência de suscitar no leitor a imaginação de que a ave tem acesso a uma outra dimensão, a um além-mundo. Duas referências a esse entendimento estão nos versos $5^{\circ}$ da $8^{\mathrm{a}}$ e da $15^{\mathrm{a}}$ estrofe, respectivamente abaixo.

\section{Tell me what thy lordly name is on the Night's Plutonian shore!" 11 \\ Is there - is there balm in Gilead? - tell me - tell me, I implore!"12}

No primeiro verso acima, ao usar a palavra Plutonian, Poe faz uma clara alusão a Plutão, o deus do reino dos mortos, para a mitologia grega. Cada pessoa morta seria julgada segundo o que fizeram em vida pelos juízes Radamanthys, Minos e Aiacos: os maus enviados para o Tártaro, os bons para os Campos Elísios. Já para

\footnotetext{
${ }^{10}$ Aliás, raven é apenas uma das variadas espécies de corvo. Esta é conhecida cientificamente como Corvus Corax.

${ }^{11}$ Diga-me o teu ilustre nome, tu que habitas a margem plutoniana da noite.

${ }^{12}$ Existe - existe bálsamo em Gileade? diga-me - diga-me, eu imploro!
} 
muitas culturas ocidentais modernas, das quais a cultura surda brasileira faz parte, Plutão é associado ao inferno, ou seja, é o responsável pelas almas em sofrimento em um mundo subterrâneo. Por isso o trecho acima motiva o leitor a imaginar o corvo como o embaixador de uma mensagem infausta do além-mundo. Como as culturas envolvidas na tradução projetam no corvo as mesmas concepções, então elas foram mantidas para que o aspecto de profeta macabro permanecesse em LiBRAs. Para preservar essa mesma referência, tomando como representatividade cultural o entendimento sobre a figura que temos de Plutão, a palavra Plutonian foi traduzida para um sinal que denota o conceito "inferno", por meio de uma variante com as mãos configuradas em forma de chifres.

Figura 1 - sinal utilizado para plutonian

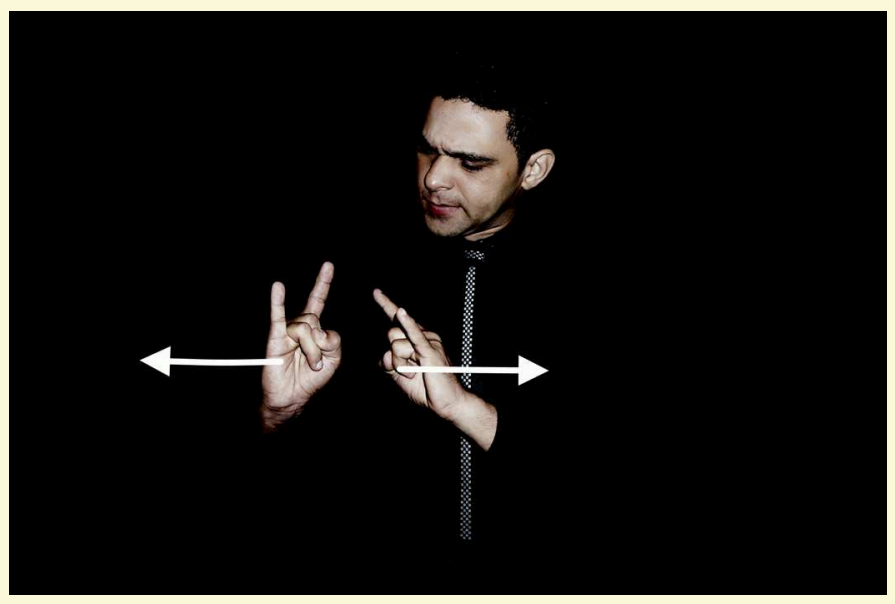

Fonte: Elaborada pelo autor

Para conservar a ideia de ambiente sepulcral elaborado pelo original funcionalmente representado na tradução, foi necessário criar todo um ambiente extralinguístico. A princípio, um cenário visual que lembrasse isolamento, medo e tristeza. Nesse sentido, 
um cenário escuro ${ }^{13}$ através do infinite black background, ou fundo infinito preto, ajudou a representar esse ambiente. Além de dar um destaque para a trama sinalizada, essa técnica faz parecer que o sinalizante está em um lugar totalmente em trevas, sem paredes, sem nada à sua volta, nem mesmo sua própria sombra é exposta. Contudo, assim como a cor preta, a branca também possui uma simbologia. Para a cultura ocidental cristã, ela simboliza paz, libertação, esperança e espiritualidade. Por isso, apesar de muitos elementos extralinguísticos na tradução indicarem escuridão, uma gravata slim de cor preta com poucos detalhes brancos foi utilizada. A escolha do branco deu-se pelo fato de que, no poema, mesmo com toda a infelicidade e devaneio visíveis, fica subentendido, em várias partes do texto, que o jovem demonstra nutrir esperança e espiritualidade, como vemos no seguinte trecho:

On this home by horror haunted - tell me truly, I implore ${ }^{14}$ Is there - is there balm in Gilead? - tell me - tell me, I implore!'

Para entender essa espiritualidade e esperança, o segundo verso acima faz alusão a uma passagem bíblica situada no livro de Jeremias 8.22. Nela, Jeremias pergunta "Será que não há bálsamo em Gileade?" em uma conjuntura que demonstra um profundo estado de tristeza, pois, segundo o texto, a nação de Judá estava espiritualmente adoecida por causa de sua infidelidade e pecado para com Deus. Se lá o Bálsamo de Gileade era usado para curar doenças e tinha finalidades medicinais, aqui Poe transporta esse fragmento bíblico para seu poema, usa uma conotação metafórica parecida com a de Jeremias e provoca no leitor a ideia de que, mesmo sofrendo a perda

${ }^{13}$ É importante destacar que a cor preta, para várias culturas ocidentais (a brasileira, por exemplo), é associada à tristeza, à morte e ao luto. Por isso, nessa estratégia visual busquei essa cor, pois a cultura de chegada foi levada em consideração. Provavelmente, se essa tradução tivesse de ser realizada para alguma comunidade cultural do oriente, a cor branca, e não a preta, seria a preferência.

${ }^{14}$ Nesta casa assombrada pelo terror - diga-me sinceramente, eu imploro. 
de sua amada Lenore, o jovem ainda mantém a esperança de ser curado, por Deus, das dores alojadas em sua alma. Na tradução, foi usada a metáfora abaixo para fazer essa mesma referenciação, muito comum nos discursos religiosos em LIBRAs, e exprime o conceito de azeite, unção ou mesmo óleo, entendidos como unguentos.

Figura 2 - sinal que representa alguma espécie de unguento derramado no coração

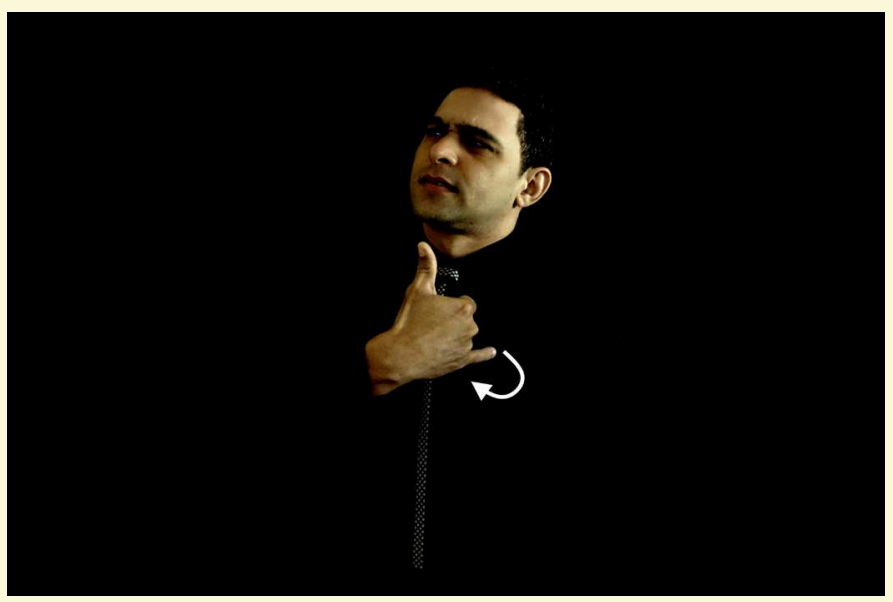

Fonte: Elaborada pelo autor

Rítmo, rima e (des)construção dos versos e das estrofes

Poe utiliza a repetição de elementos fonéticos para dar sonoridade a todo o poema. Um bom exemplo disso encontra-se no verso And the silken sad uncertain rustling of each purple curtain ${ }^{15}$. A repetição das consoantes s, s, c, s, representadas fonologicamente por $/ \mathrm{s} /$, conferem ao verso um ruído semelhante ao de um tecido sedoso sendo sacudido pelo sopro do vento. Essa peculiaridade fo-

$\overline{{ }^{15} \mathrm{E} \text { o triste farfalhar sedoso e incerto de cada cortina roxa. }}$ 
nética deu espaço aos classificadores e aos morfismos. Este último pode ser mais bem explorado quando o sinalizante aproveita o ponto de encontro entre dois sinais para fundir um ou mais parâmetros, geralmente o movimento e a configuração de mãos. Isso ocorre quando um dos parâmetros do primeiro sinal, antes de se encerrar, é aproveitado por um parâmetro semelhante ao do sinal que o sucede, proporcionando uma harmonia entre ambos. Essa fusão paramétrica, da forma que foi explorada na tradução, proporcionou uma sinalização ritmada e poética.

Com relação aos classificadores, Quadros e Karnopp (2004, pp. 92-93) fornecem-nos importantes considerações, destacando que eles compõem o léxico da LiBRAs, mas possuem propriedades morfológicas distintas, em que a configuração de mão especifica qualidades, movimentos e posição de objetos, pessoas e animais. A aliteração citada acima, por exemplo, cedeu espaço a um classificador que descreve a cortina sendo balançada pelo vento.

Figura 3 - classificador indicando o movimento da cortina

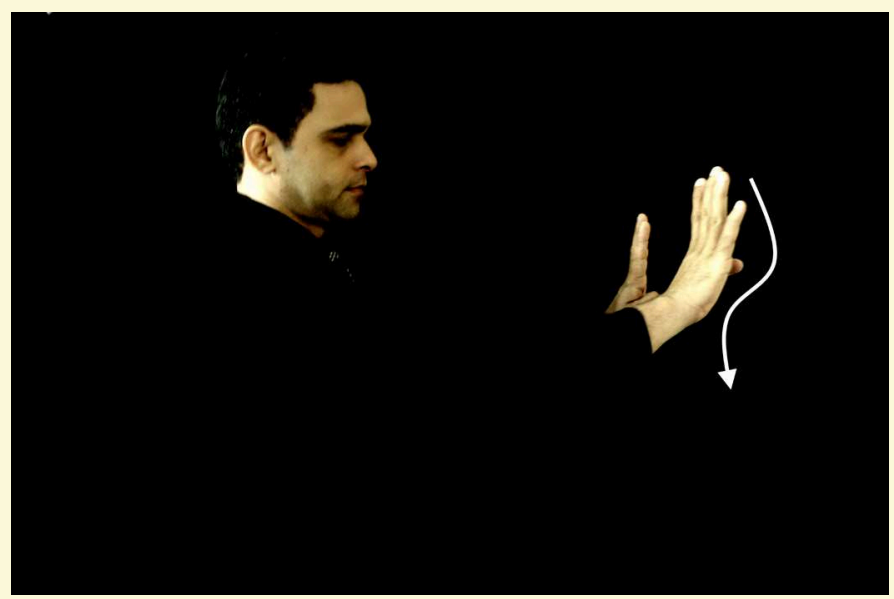

Fonte: Elaborada pelo autor 
Além da aliteração presente na maior parte do poema original, a esquematização regular das rimas, enquanto a posição na estrofe, segue um padrão conforme pode ser visto abaixo.

Ah, distinctly I remember it was in the bleak December, And each separate dying ember wrought its ghost upon the floor. B Eagerly I wished the morrow; - vainly I had sought to borrow $C$ From my books surcease of sorrow - sorrow for the lost Lenore - B For the rare and radiant maiden whom the angels name Lenore - B Name less here for evermore. $B$

Naturalmente, para ser considerado um poema, o texto não precisa ser composto por um padrão métrico, nem necessariamente precisa possuir rimas entre seus versos. O Modernismo introduziu os versos não rimados e livres de metrificação regular. Contudo, em The raven encontramos uma estrutura padronizada. Da mesma forma, a tradução foi pensada e estabelecida com o objetivo de conservar um padrão que realçasse rimas e ritmo. Aliás, este último não é propriedade exclusiva das músicas. O movimento das marés, a órbita dos corpos celestes, o vaivém da copa de uma árvore, o voo frenético de um beija-flor, a agitação de pessoas em uma dança, a organização das palavras em um poema demonstram que para se produzir ritmo a voz não se faz necessária, o corpo pode executar muito bem esse papel. Pensando nisso, a tradução explorou o corpo por meio de uma série de classificadores, morfismos e reverberação paramétrica com o intuito de gerar um determinado ritmo poético em LIBRAS. Mesmo assim, é importante destacar que, em línguas de sinais, os estudos sobre rimas e versos ainda estão expandindo-se. Bauman (2003) faz referência a Clayton Valli como um dos primeiros pesquisadores a tratar especificamente dos versos e das rimas em língua de sinais. Seu trabalho seminal intitulado 
The Nature of the Line in ASL Poetry promoveu importantes reflexões, estabelecendo as características básicas da poesia em língua de sinais e apontando diferenças e semelhanças com os poemas produzidos em língua oral-auditiva.

Apesar do significativo trabalho de Valli (1987), é importante destacar a contribuição de Klima e Bellugi (1976), que também evidenciaram a possibilidade de se explorar os sinais para produzir padrões ritmados e rimados. Para gerar esses padrões, o sinalizante pode valer-se de vários recursos, entre eles estão a repetição de um mesmo parâmetro em vários sinais, a alternância rítmica das mãos e o uso dos pontos de articulação, de forma que eles estabeleçam correspondência entre dois ou mais sinais. Mesmo assim, uma convergência entre pesquisadores (cf. Klima e Bellugi, 1976; Valli, 1987; Russo, Giuranna e Pizzutu, 2001; Bauman, 2003) é a de que a estratégia de repetição paramétrica dos sinais promove a rima. Essa reverberação, ou seja, essa repetição de parâmetros pode dar-se de duas maneiras, pelo menos: (i) quando em um par de sinais apenas um dos parâmetros permanece diferente, ou (ii) quando apenas um parâmetro é compartilhado por dois ou mais sinais. No primeiro caso, a rima torna-se mais acentuada do que no segundo. As imagens abaixo mostram essa reverberação.

Figura 4 - reverberação paramétrica

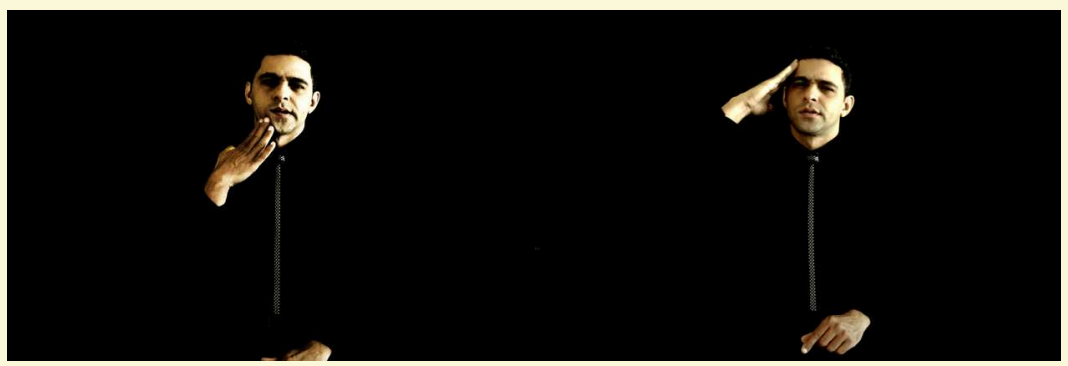




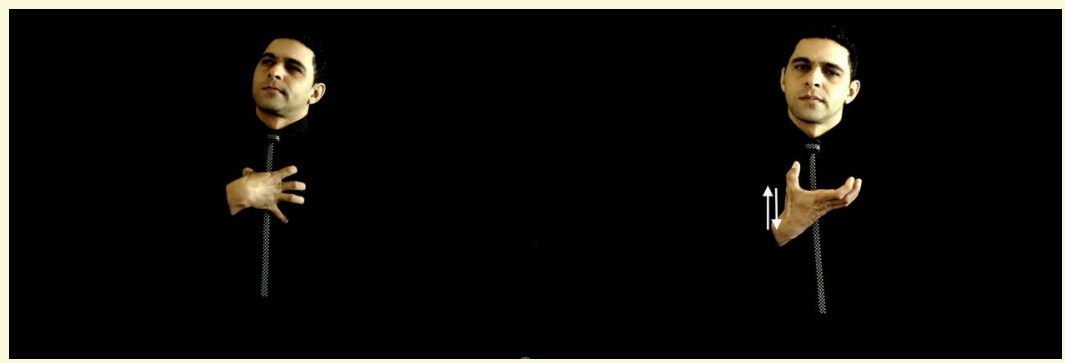

Fonte: Elaborada pelo autor

No primeiro par de sinais (da esquerda para a direita), é possível perceber uma mudança efetiva no parâmetro "Ponto de Articulação": enquanto no primeiro sinal a atividade da mão é realizada no queixo, no segundo é a testa que recebe a ação. Todos os outros parâmetros permanecem iguais. Já no segundo par, apenas a configuração de mãos é semelhante, todos os outros parâmetros são diferentes. Mesmo assim, embora o efeito seja menos acentuado, é mais comum que as rimas em línguas de sinais ocorram a partir do compartilhamento de apenas um parâmetro. E apesar da simetria na tradução, a reverberação paramétrica não segue a rima do texto-fonte, i.e., os sinais em que aconteceram as rimas não possuem relação de sentido com os pares de palavras rimadas do original, como pode ser percebido na amostra abaixo.

Quadro 1 - amostra de rimas e reverberação paramétrica da segunda estrofe

\begin{tabular}{|l|l||l|l|}
\hline \multicolumn{2}{|c||}{ Rimas do original } & \multicolumn{2}{c|}{ Rimas da tradução } \\
\hline $\begin{array}{l}\text { Dreary } \\
\text { [triste] } \\
\left(1^{\circ} \text { verso }\right)\end{array}$ & $\begin{array}{l}\text { Weary } \\
\text { [cansado] } \\
\left(1^{\circ} \text { verso }\right)\end{array}$ & \multicolumn{1}{|c|}{} \\
& $\begin{array}{l}\text { SENTIR [sensação } \\
\text { de pesar] } \\
\left(1^{\circ} \text { verso }\right)\end{array}$ & $\begin{array}{l}\text { DEZEMBRO } \\
\left(1^{\circ} \text { verso }\right)\end{array}$ \\
\hline
\end{tabular}

Cad. Trad., Florianópolis, v. 37, no 2, p. 132-158, mai-ago 2017 


\begin{tabular}{|c|c|c|c|}
\hline \multirow[b]{3}{*}{$\begin{array}{l}\text { floor } \\
\text { [chão] } \\
\left(2^{\circ} \text { verso }\right)\end{array}$} & $\begin{array}{l}\text { Lenore } \\
\left(4^{\mathrm{o}} \text { e } 5^{\mathrm{a}}\right. \\
\text { versos })\end{array}$ & & $p^{9}$ \\
\hline & 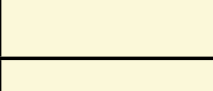 & & $\begin{array}{ll}\text { MORRER } & \text { LEONORA } \\
\left(4^{\circ} \text { verso }\right) & \left(5^{\circ} \text { versos }\right)\end{array}$ \\
\hline & $\begin{array}{l}\text { Evermore } \\
\text { [eternamente] } \\
\left(6^{0} \text { verso }\right)\end{array}$ & $\begin{array}{l}\quad \\
\text { CHÃO } \\
\left(2^{\circ} \text { verso }\right)\end{array}$ & $\underset{-\infty}{\text { ACABAR }}$ \\
\hline \multirow{4}{*}{$\begin{array}{l}\text { morrow } \\
\text { [dia } \\
\text { seguinte] } \\
\left(3^{\circ} \text { verso }\right)\end{array}$} & $\begin{array}{l}\text { borrow } \\
\text { [tomar } \\
\text { emprestado) } \\
\left(3^{\circ} \text { verso }\right)\end{array}$ & & ail \\
\hline & & $-\infty$ & $\begin{array}{l}\text { ME-AJUDAR } \\
\left(3^{\circ} \text { verso }\right)\end{array}$ \\
\hline & $\begin{array}{l}\text { Sorrow } \\
\text { [tristeza] } \\
\left(4^{\circ} \text { verso }\right)\end{array}$ & $\begin{array}{l}\text { SOL-NASCER } \\
\left(3^{\circ} \text { verso }\right)\end{array}$ & 8 \\
\hline & & & $\begin{array}{l}\text { PASSAR } \\
\text { [no sentido de ter um } \\
\text { fim, acabar] } \\
\left(3^{\circ} \text { verso }\right)\end{array}$ \\
\hline
\end{tabular}

Fonte: Elaborada pelo autor 


\section{Ênfase na experiência visual}

Antes do processo tradutório, foram observados vários comportamentos da ave, por meio de vídeos e textos disponíveis na internet. Dois desses comportamentos merecem destaque, porque foram eles que motivaram a utilização de alguns dos classificadores: o voo e o grasnar. Quando o corvo voa, pelo menos cinco penas na extremidade de cada asa são bem visíveis, por isso essa característica foi explorada pela tradução utilizando um classificador que lembra as penas e o bater das asas. O segundo comportamento está relacionado com o movimento de cabeça para cima e para baixo produzido pelo corvo ao emitir um de seus sons guturais. Na tradução, esse movimento foi explorado por um classificador que dá a sensação visual de que a ave está emitindo um som, e, ao mesmo tempo, a configuração de mão em conjunto com o movimento indica o sinal NUNCA ${ }^{16}$ Como o objetivo da tradução era tornar o texto funcionalmente representativo na cultura de chegada, essa estratégia foi utilizada para fazer referência à palavra nevermore. Por isso, todas as respostas produzidas pelo corvo foram representadas por meio de um classificador que sugere, ao mesmo tempo, o movimento de cabeça da ave, o som emitido por ela e a sensação da resposta negativa NUNCA/NUNCA MAIS.

Os trechos abaixo foram alguns dos que impeliram o uso de classificadores. Os mesmos representam, respectivamente, o balançar da porta, o amanhecer figurado pelo movimento do sol, o balançar da cortina na janela, o voo da ave, a posição do corvo no busto de Pallas e o aspecto de seu bico ao emitir o som.

${ }^{16}$ O sinal "NUNCA" também pode significar "nunca mais", a depender do contexto de utilização, apesar de existir um sinal específico para cada um. Na tradução, com o uso do classificador que indica o movimento de cabeça da ave para cima e para baixo, com o seu bico abrindo e fechando, o interlocutor tem a sensação de que há ali uma referência tanto ao sinal "NUNCA" como ao significado "nunca mais".

Cad. Trad., Florianópolis, v. 37, n $^{0}$ 2, p. 132-158, mai-ago 2017 
Quando 2 - alguns classificadores usados

\begin{tabular}{|c|c|c|c|}
\hline $\begin{array}{l}\mathrm{N}^{\mathrm{o}} \\
\text { Estrofe }\end{array}$ & $\begin{array}{l}\text { Parte do verso que } \\
\text { recebeu o classificador }\end{array}$ & Verso & Classificadores \\
\hline $1^{\mathrm{a}}$ & $\begin{array}{l}{[\ldots] \text { there came a }} \\
\text { tapping }\end{array}$ & $1^{0}$ & \\
\hline $2^{a}$ & {$[\ldots]$ the morrow $[\ldots]$} & $3^{\circ}$ & \\
\hline $3^{a}$ & $\begin{array}{l}\text { And the silken sad } \\
\text { uncertain rustling of } \\
\text { each purple curtain }\end{array}$ & $1^{\mathrm{o}}$ & \\
\hline $7^{a}$ & $\begin{array}{l}{[\ldots] \text { with many a flirt }} \\
\text { and flutter }\end{array}$ & $1^{\circ}$ & \\
\hline
\end{tabular}




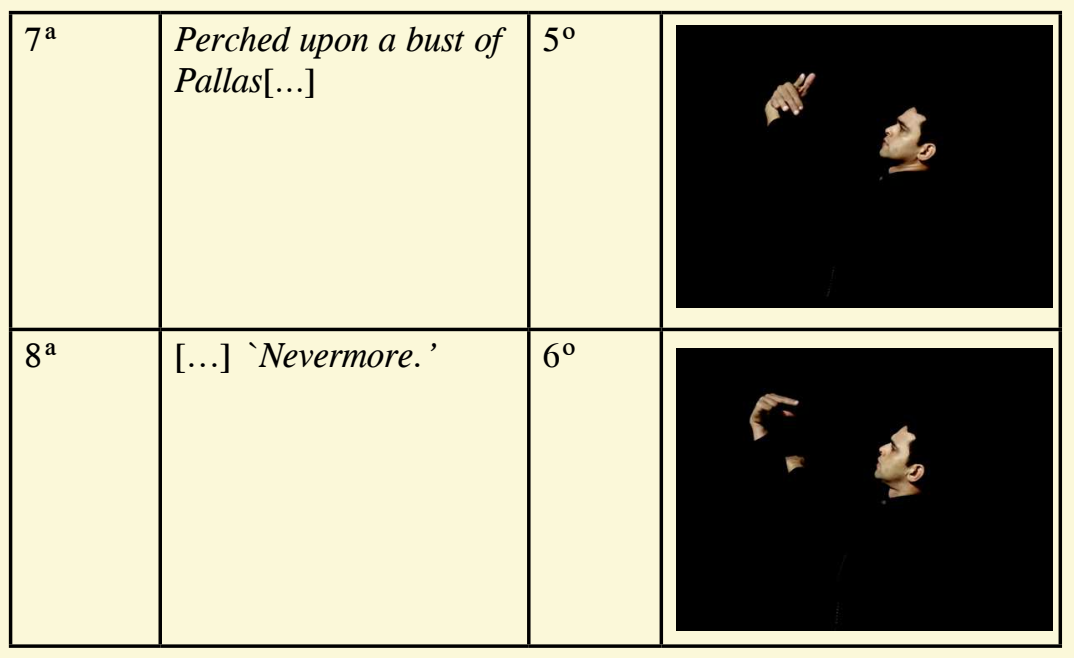

Fonte: Elaborada pelo autor

Sempre que possível, as expressões sonoras ou palavras que destacam intencionalmente a sonoridade presente no texto original não foram excluídas, mas substituídas por classificadores ou mesmo sinais, como aconteceu com nevermore e com a aliteração de And the silken sad uncertain rustling of each purple curtain. $\mathrm{Na}$ quinta estrofe, para citar mais um exemplo, as palavras word, spoken, whispered, echo e murmured ${ }^{17}$ foram substituídas por sinais que respectivamente exprimem o conceito de "significado", "perceber", "produzir", "responder" e "sentir". Essa postura também foi adotada porque o som, ou as referências a ele, possui pouco espaço nas poesias em línguas de sinais, e a ênfase na experiência visual para a pessoa surda é um item essencial. Sutton-Spence e Quadros (2008, p. 117) destacam essa asserção da seguinte forma: "o som - e a ausência dele - tem lugar muito pequeno nessas poesias e é raro encontrar um poema na língua de sinais que foque

\footnotetext{
${ }^{17}$ Palavra, falou, sussurrou, eco e murmurou. Obviamente, o processo tradutório não teve o interesse de fazer uma tradução palavra por palavra. Algumas escolhas foram feitas para possibilitar uma estrutura formal poética, por meio da reverberação paramétrica.
} 
em qualquer sentido a perda da audição para pessoas surdas." As autoras também elencam algumas maneiras pelas quais "o poeta pode trazer a experiência visual para o primeiro plano", entre elas estão o uso de itens lexicais manuais e não-manuais. Nos manuais, o sinalizante pode empregar explicitamente os verbos que fazem alusão ao olhar; nos não-manuais, o poeta movimenta os olhos para indicar a própria ação.

Mesmo assim, como a tradução seguiu uma orientação intercultural, e como a comunidade surda é constituída também por ouvintes (tradutores/intérpretes e outras pessoas fluentes em LIBRAS), de alguma forma percebi a necessidade de explorar a sonoridade. Por isso, vários efeitos foram utilizados, tais como ruído de porta abrindo, som de madeira queimando, barulho de vento e chuva, trovoadas etc., explorando as experiências sensoriais dos ouvintes. Dessa forma, enquanto parte dos recursos extralinguísticos da tradução explorou a experiência visual do surdo (cenário, roupa, pouca iluminação etc.), outra parte explorou a experiência auditiva dos ouvintes, mas a sinalização em si excluiu referências ao som, porque a intenção também foi promover no espectador a impressão de que a personagem criada por Poe, levando em consideração a tradução para a LIBRAs, obviamente, poderia tratar-se de uma personagem surda. Por exemplo, logo na primeira estrofe, quando o poema original narra os sons onomatopaicos de toque na porta, a tradução utilizou um classificador que destaca uma porta movimentando-se, enquanto o jovem olha atentamente para ela. Isso produz no espectador do vídeo a impressão de que a personagem percebe o movimento da porta, não o som.

Ao analisar os poemas Three Queens (Três Rainhas, do poeta surdo britânico Paul Scott) e Bandeira Brasileira (do poeta surdo Nelson Pimenta) Sutton-Spence e Quadros (2008, p. 119) chamam atenção para o fato de que o olhar dos dois poetas é usado para atrair o foco da plateia para o objeto observado pelo produtor do poema. Pimenta, por exemplo, ao soletrar o lema "ordem e progresso", direciona o olhar para as mãos, como uma maneira de realçar a importância do nome soletrado. A mesma estratégia de 
trazer ao primeiro plano a experiência visual foi usada em várias partes da tradução deste trabalho, mas há duas que merecem destaque. A primeira usa um classificador que indica o corvo parado olhando a personagem, enquanto esta dialoga com ele.

Figura 5 - classificador indicando o olhar do corvo para a personagem

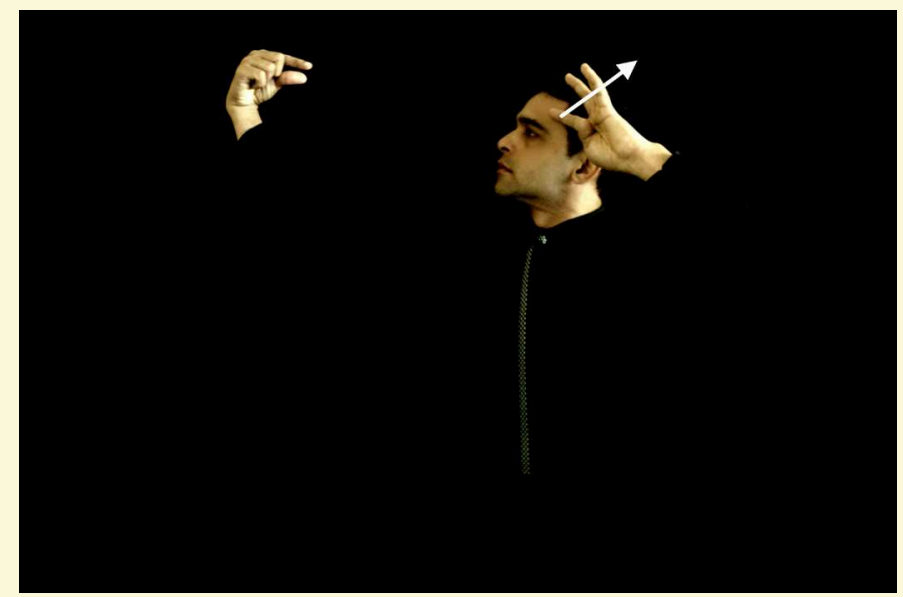

Fonte: Elaborada pelo autor

A segunda está relacionada com a tradução do trecho final do quarto verso da segunda estrofe: sorrow for the lost Lenore ${ }^{18}$. Aqui, há três observações relevantes: a primeira concerne à opção de soletrar manualmente a palavra Leonora ao invés de Lenore, posto que antes da tradução pensei em um público-alvo constituído também por ouvintes falantes de língua portuguesa e fluentes em LiBRAs. Deste modo, a segunda palavra é mais representativa para a cultura de chegada. A segunda observação refere-se ao olhar voltado para a mão no momento em que a palavra Leonora é soletrada, denotando um certo sentimento de amor, de saudade e

${ }_{18}$ Tristeza pela perda de Lenore.

Cad. Trad., Florianópolis, v. 37, no 2, p. 132-158, mai-ago 2017 
de tristeza. A terceira diz respeito a mais um aspecto cultural da comunidade surda: o sinal de identificação para Lenore, com a configuração de mão em "B" e um movimento que descreve o cabelo levemente ondulado caindo sobre os ombros.

Figura 6 - sinal de identificação da personagem Lenore

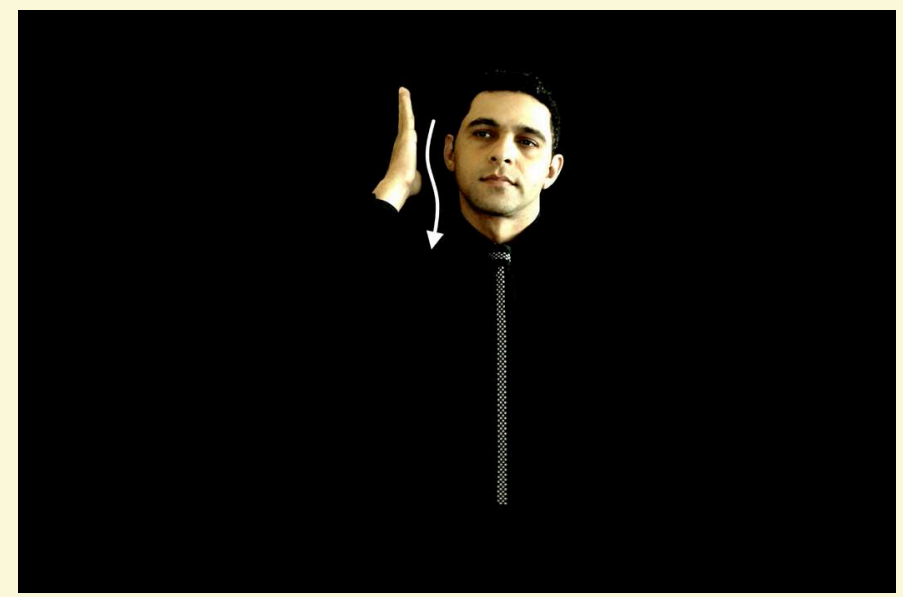

Fonte: Elaborada pelo autor

Com o sinal de identificação criado, foi possível manter e evidenciar as rimas configuradas em "B", inclusive com os classificadores, como aqueles que indicam o bater das asas do corvo e sua posição no busto de Pallas.

Para finalizar, acredito que as estratégias utilizadas na tradução tornaram alguns aspectos mais acentuados do que outros, tais como: 


\begin{tabular}{|c|c|c|}
\hline Aspectos da tradução & $\begin{array}{l}\text { Possibilidade de } \\
\text { identificação }\end{array}$ & OBS \\
\hline Versos & Em menor grau & $\begin{array}{l}\text { Com a tradução } \\
\text { fluida, os versos } \\
\text { só são percebidos } \\
\text { quando analisados } \\
\text { minuciosamente em } \\
\text { comparação com o } \\
\text { original. }\end{array}$ \\
\hline Estrofes & Em maior grau & $\begin{array}{l}\text { Com o desvanecimento } \\
\text { de vídeo, as estrofes } \\
\text { ficaram em destaque. } \\
\text { Caso se pense em uma } \\
\text { tradução ao vivo, o } \\
\text { tradutor poderia valer- } \\
\text { se de outras estratégias } \\
\text { - pausas e mudança de } \\
\text { posição do corpo, por } \\
\text { exemplo. }\end{array}$ \\
\hline Rimas & Em maior grau & $\begin{array}{l}\text { Tanto nas internas } \\
\text { como nas externas, } \\
\text { as reverberações } \\
\text { paramétricas } \\
\text { possibilitaram as rimas. } \\
\text { Mas como dito, os } \\
\text { estudos sobre como se } \\
\text { configuram as rimas em } \\
\text { línguas de sinais ainda } \\
\text { estão ampliando-se. }\end{array}$ \\
\hline Estrutura poética & Em maior grau & $\begin{array}{l}\text { A forma como a } \\
\text { tradução foi organizada } \\
\text { e como a linguagem foi } \\
\text { utilizada possibilitou } \\
\text { uma produção poética. }\end{array}$ \\
\hline
\end{tabular}




\section{Considerações finais}

As estratégias elaboradas pela tradução deste trabalho baseiam-se na concepção de que há textos propícios a se tornarem um artefato da cultura de chegada, assim como o original é para a cultura de partida. A LiBrAs, por exemplo, possibilitou explorar muitos recursos extralinguísticos e visuais não explícitos no texto-fonte, mas subentendidos no poema e revelados pela leitura idiossincrática de um novo ser cultural. Com essa perspectiva, um texto como The raven pode ganhar sua representatividade cultural na língua de chegada a cada nova tradução, sem excluir sua essência lúgubre, sombria, melancólica, infeliz etc. A propósito, sobre esse aspecto, Nord (1991) defende a ideia de que o próprio tradutor é também um produtor de textos para os membros culturais da língua de chegada, sendo um agente como aquele da língua de partida. E além de toda a intenção intercultural, a tradução também objetivou assegurar uma estrutura cadenciada, a fim de evidenciar uma conotação poética.

Assumindo esses princípios, é possível, até certa medida, oferecer um texto funcionalmente representativo como mais um produto do código simbólico de quem espera a tradução. Como tradutores, diante de alguns textos, portanto, talvez valesse a pena refletir em como o texto de partida está representado funcionalmente na cultura de partida e como seria sua representação funcional na cultura de chegada. A partir disso, os elementos que necessitam ser preservados, excluídos ou mesmo adaptados parecem saltar aos olhos do tradutor. E este se desloca para uma realidade vivenciada pelo outro ser cultural, observando e analisando não apenas os códigos linguísticos mas também boa parte daquilo que subjaz às línguas envolvidas na tradução. 


\section{Referências}

BAUMAN, L. Redesigning literature: the cinematic poets of American Sign Language poetry. Sign Language Studies. Vol. 4, Nº. 1. Fall, 2003.

D'ANDRADE, R.G. The Development of Cognitive Anthropology. Cambridge: Cambridge University Press, 1995.

HUDSON, R. A. Sociolinguistics. 2nd edn. Cambridge: Cambridge University Press, 1996.

KLIMA, E.; BELLUGI, U. The Signs of Language. Cambridge, Mass: Harvard University Press, 1979.

KÖVECSES, Z. Metaphor in Culture: universality and variation. New York: Cambridge University Press, 2005.

KÖVECSES, Z. Metaphor, Language, and Culture. São Paulo: Documentação de Estudos em Linguística Teórica e Aplicada - D.E.L.T.A., 26: especial, pp. 739-757. 2010.

LAKOFF, G.; JOHNSON, M. Metaphors We Live by. Chicago: University of Chicago Press, 2003.

LAKOFF, G.; JOHNSON, M. Philosophy in the Flesh: The Embodied Mind and Its Challenge to Western Thought. New York: Basic Books, 1999.

LYONS, J. Linguagem e Linguística: uma introdução. Traduzido por Clarisse Sieckenius de Souza e Marilda Winkler Averburg. Rio de Janeiro: LTC, 2013.

NORD, C. Text Analysis in Translation: Theory, Methodology, and Didactic Application of a Model for Translation-Oriented Text Analysis. Amsterdam: Rodopi, 1991.

POE, E. A., The Raven. Disponível em < http://www.poetryfoundation.org/ poem/178713 > Acesso em: 26 de maio de 2015 . 
QUADROS, R. M.; KARNOPP, L. B. Lingua brasileira de sinais: estudos linguísticos. Porto Alegre: Artmed, 2004.

REISS, K. Type and individuality of text: decision marking in translation. Translated by Susan Kitron. In: VENUTI, L., (ed). The translation studies reader. New York, NY: Routledge, 2000.

RUSSO, T.; GIURANNA, R.; PIZZUTU, E. Italian Sign Language (LIS) poetry: iconic properties and structural regularities. Sign Language Studies. Vol. 2, pp. 84-112. Fall, 2001.

SANTOS, E.C.P. Metáforas conceituais baseadas em vida, morte e ressurreição e sua tradução para a Libras. Dissertação (Mestrado em Estudos da Tradução) Fortaleza: Universidade Federal do Ceará, 2016.

SHORE, B. Culture in mind: Cognition, Culture, and the Problem of Meaning. New York: Oxford University Press, 1996.

STRAUSS, C.; QUINN, N. A. Cognitive Theory of Cultural Meaning. Publications of the Society for Psychological Anthropology. $N^{\circ}$. 9. Cambridge: Cambridge University Press. Available from: Cambridge Books Online. Disponível em: < http://dx.doi.org/10.1017/CBO9781139167000 > Acesso em 16 de fevereiro de 2016.

SUTTON-SPENCE, R.; QUADROS, R. M. Poesia em línguas de sinais: traços da identidade surda. In: QUADROS, R. M.(Org). Estudos Surdos I. Perópolis, RJ: Arara Azul, 2006.

VERMEER, H. J. Skopos and commission in translation action. In: VENUTI, L., (ed). The translation studies reader. New York, NY: Routledge, 2000.

WITHERSPOON, G. Language and Art in the Navajo Universe. Ann Arbor: University of Michigan Press, 1977.

Recebido em: 27/10/2016

Aceito em: 20/02/2017

Publicado em maio de 2017 